\title{
Chapter 9 \\ Innovative Monitoring Techniques \\ for Wadi Flash Flood by Using \\ Image-Based Analysis
}

\author{
Mahmood M. Al-Mamari, Sameh A. Kantoush, and Tetsuya Sumi
}

\begin{abstract}
Flash floods in wadi systems are a very important environmental issue, and their monitoring is necessary for many applications, including water resource management, irrigation and flood control. However, monitoring networks are very rare and lack spatial distribution features. In this study, image-based techniques were used to quantify and monitor flash floods in wadi channels by using two different methods. In the first section, we employed photogrammetry processing technique to quantify post-peak flood discharges by using a drone survey to build a digital elevation model (DEM) with a high resolution and calibrated and validated the model with a field survey (levelling measurements). This technique used drone-collected images to construct a DEM for extracting a cross-sectional profile and elevation points to calculate the peak discharge using the slope-area method with the Manning equation. In the second section, we combined the previous technique with the large-scale particle image velocimetry (LSPIV) technique to measure flash flood discharge by installing a fixed camera on a road bridge crossing a wadi channel and using a digitally extracted cross section from the DEM in the analysis. The results of those techniques show a high efficiency that is equivalent to that of conventional methods.
\end{abstract}

Keywords Flash flood - Wadi • Monitoring - Image analysis • Photogrammetry • LSPIV

M. M. Al-Mamari $(\bowtie) \cdot$ S. A. Kantoush · T. Sumi

Disaster Prevention Research Institute (DPRI), Kyoto University, Kyoto 611-0011, Japan

e-mail: almamari.mahmood.78c@st.kyoto-u.ac.jp

S. A. Kantoush

e-mail: kantoush.samehahmed.2n@kyoto-u.ac.jp

T. Sumi

e-mail: sumi.tetsuya.2s@kyoto-u.ac.jp

(C) The Author(s) 2022

T. Sumi et al. (eds.), Wadi Flash Floods, Natural Disaster Science and Mitigation

Engineering: DPRI Reports, https://doi.org/10.1007/978-981-16-2904-4_9 


\subsection{Introduction}

Precipitation is the main source of water in semiarid and arid regions. The variables of rainfall patterns are intricate with irregular frequencies. However, the intensity and duration of rainfall play the main roles in hydraulic processes in dry environments. Arid regions have many challenges associated with water stress and desertification due to high temperatures and water demands (Sen 2008). Effective water resource management is very important for human and environmental sustainability. In recent years, extreme rainfall events have increased; consequently, flash floods occur more frequently with high discharges. Additionally, massive destruction to infrastructure and properties and human losses have occurred in the last decade in arid regions due to hazardous disasters such as flash floods. However, many countries in dry environments face water resource shortages and drought because of improper management and monitoring. In Middle East countries and North Africa, the term 'wadi' is used to refer to an ephemeral channel or valley. Wadi systems are different from river systems due to their scientific and flow dynamics. Run-off in wadi is mainly dependent on the availability of rainfall events, with rapid peaks of water occurring in streams for short periods. The critical issue concerning wadi flash floods is the availability of hydrological data, and observational data is lacking in this area. There are several challenges involved in wadi monitoring; for instance, access to gauges during flash floods can be impossible, and technical problems with inapplicable instruments measuring flow dynamics (discontinued flow) and sediment load (instrument protection housing clogged up with sediment) can occur, as well as the destruction of hydrometric stations.

Recently, many studies have been conducted to simulate flash floods in wadi basins; however, the efficiency of these models is limited by the observed data (Abdel-Fattah and Kantoush 2016). Many arid countries have requested inexpensive and adaptable techniques for qualitative and quantitative hydrology and water resources due to the ephemeral conditions of wadi basins. To manage and monitor wadi flash floods in arid regions, this chapter presents new methods and approaches by using image-based techniques. Therefore, the monitoring and measurement of wadis are tools used to improve and achieve better management systems. The use of image-based techniques to monitor and quantify flash floods will assist in upgrading hydrological databases with higher accuracies, faster analyses and early warning systems. Therefore, we can integrate our water resource management by mitigation structures, water resource policies/strategies and aquifer management recharge. Additionally, these techniques will provide real-time visual warning systems for flash floods in basins, which will help to prevent and warn downstream communities about strengthening flash floods, and can be used to manage dam operations for the release and storage of water in dam reservoirs during severe conditions.

First, we will discuss image analysis for monitoring wadi flash floods in arid regions. Wadi flash floods are rapid run-off events of peak discharges over dry channel beds. Typically, these events are under-monitored and under-investigated 
and are forecasted based on rainfall magnitudes (Smith et al. 2014). In general, the impacts of climate change are expected to include the potential for more changes in rainfall intensities and temperature levels. Accurate field observations of wadi flash floods will provide a scientific understanding of flood characterizations that can help improve future flood forecasting and management. The use of direct and indirect measurements of discharge was possible with image-based techniques. The aim of this section is to provide alternative techniques to estimate peak post-flood discharge in wadi systems.

In the second section, we will discuss the large-scale particle image velocimetry (LSPIV) technique to monitor and measure flash flood discharge as a new method for wadi systems. LSPIV is a method used to measure surface flow velocity by using pairs of images extracted from recorded videos of flash floods. The first systematic study using LSPIV was carried out in 1998 by Fujita et al. (1998) for river systems. This technique is a noncontact measurement that can monitor flash floods from safe places and can provide a real-time monitoring system. The main advantages of this technique are the inexpensiveness, adequate accuracy and geographic extent of the measured surface water. This technology has been widely investigated in river basins (Harpold et al. 2006; Sun et al. 2010; Coz et al. 2010). This paper reports and investigates the performance of using image-based techniques in wadi systems to quantify post-peak discharges and real-time flow rates. The accuracy of LSPIV was evaluated in wadi flash floods, and the outputs seem to be very plausible (Al-Mamari et al. 2019). LSPIV can measure flash flood discharge with an accuracy comparable to that of local point measurements (current meter, transducer sensor and radar water level), which are the most common monitoring methods employed to measure water levels and compute discharges by using a rating curve. In addition, the conventional method of monitoring wadi flash floods is always influenced by technical issues due to dry seasons and the lack of recorded data as well as changing sediment loads and bed channels. Therefore, this work shows that innovative monitoring techniques can be used to obtain noncontact measurements and extract powerful information and data from wadi channels. The case study was from Wadi Aluqq in Oman, where a flood event occurred in October 2018 with a medium flow. We successfully estimated the flow rate at three phases (rising, peak and recession) and compared the results with those obtained from the conventional method (slope-area method). The resultant flood discharge from the rating curve was $6.3 \mathrm{~m}^{3} / \mathrm{s}$, and the LSPIV-estimated discharge showed very good agreement, with a value of approximately $6.4 \mathrm{~m}^{3} / \mathrm{s}$. The proposed monitoring techniques could provide high-quality measurements of wadi flow discharges without the need to visit the field during flash flood events, which is challenging work. 


\subsubsection{Conventional Monitoring Techniques and Methods in Wadi Systems}

Water resource management requires highly precise observation data collected using different equipment and methods for monitoring and early warning systems to prevent threats to humans and infrastructure. Many techniques have been utilized to monitor wadi flash floods, such as crest stage indicators (gauges), water level transducers and radar water levels (Fig. 9.1) (Public Authority for Water Resource 1983). However, these techniques represent local point observations, which deliver some uncertainty when used to calculate discharge. The slope area method is an indirect measurement used to estimate peak discharge after a flood occurs by using a channel geometry technique that was developed in the Western USA (Johnson 1977). We define the relationship between the channel geometry and flood level, which is utilized to develop a rating curve based on the accumulation of slope-area measurements. This method is applied by using the Manning equation and the principle of conveyance. For this method, three or more cross sections of the wadi channel are required with estimated roughness coefficients. The accuracy of this method is dependent on the visibility and availability of flood markers, which present water level markers in the channel embankment (Dalyrmple and Benson 1967). Therefore, the combination of observed data obtained by monitoring techniques (transducer water levels and radar water levels) and rating curves can be used to analyse daily or hourly discharge in wadi channels. Figure 9.2 shows the equipment used to conduct the slope-area method in a wadi channel. Recently, survey instruments have been improved with higher accuracies and easier-to-obtain surface levelling. However, the main disadvantage of these devices is that they are very expensive and highly sensitive to weather conditions.
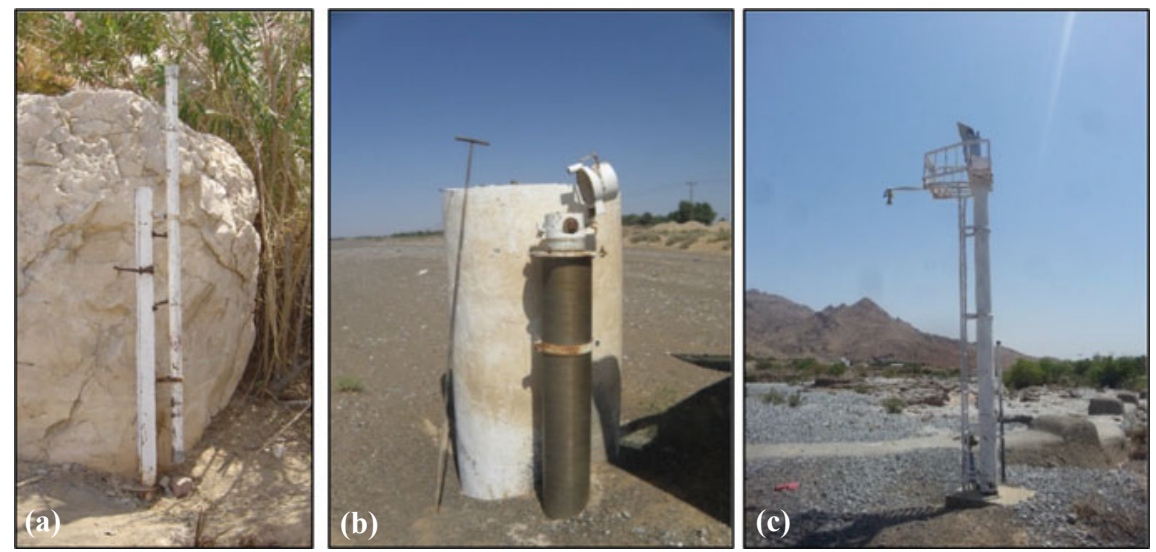

Fig. 9.1 a Crest stage indicator; $\mathbf{b}$ transducer inside a protection screening filter; $\mathbf{c}$ radar water level 

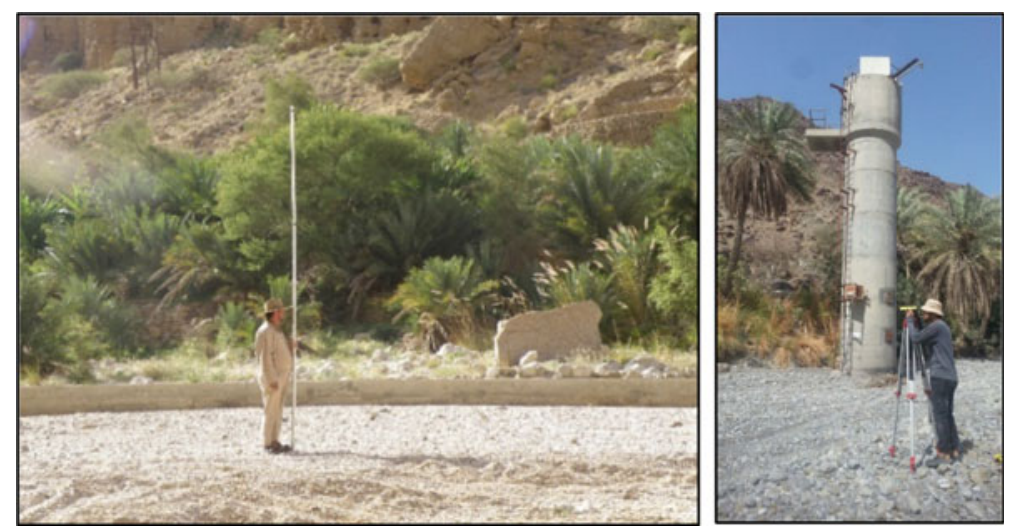

Fig. 9.2 Slope-area method using levelling instruments

Current meter measurements were used to measure the flow rates of low discharges (base flows) in wadis (Fig. 9.3). To measure the average discharge, we divide the width of the surface flow in the wadi channel into several sections and measure the velocity of each section; then, we multiply the average velocity by the cross-sectional area to give the total discharge. Wadi systems in arid regions are characterized by high drainage densities with complex topographic features. Therefore, these systems require widespread hydrologic monitoring networks to achieve integral water resource balance in wadi basins.
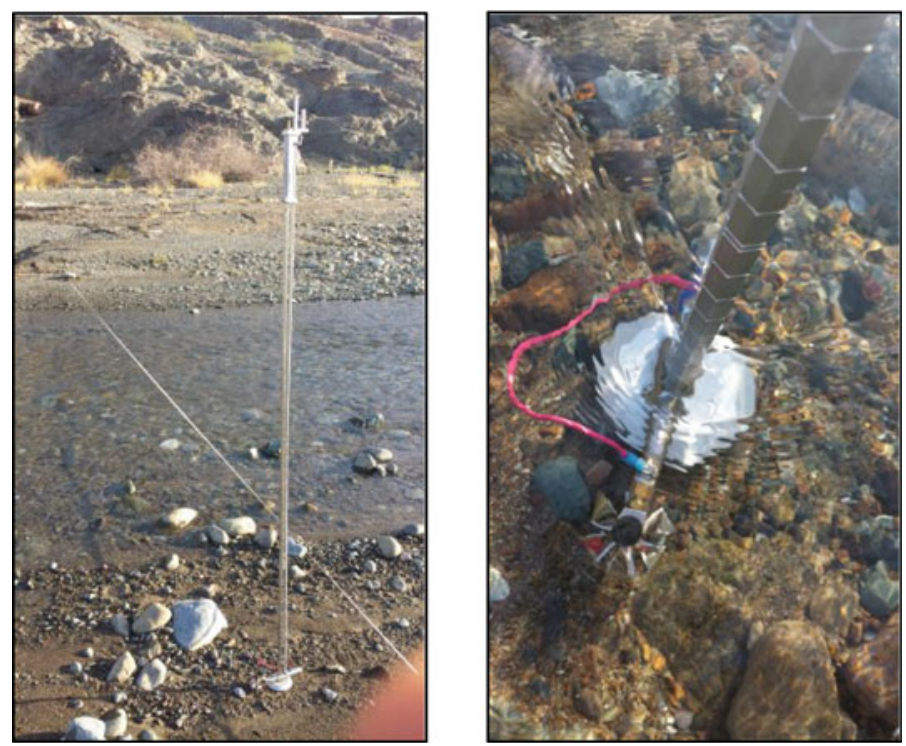

Fig. 9.3 Current meter measurement method 


\subsection{Image-Based Techniques}

Currently, image processing analysis is a widespread technique used to extract large amounts of data and information. In the literature, there are several examples of using image-based techniques for monitoring water surfaces (Muto et al. 2002; Fujita et al. 2019; Detert and Weitbrecht 2015). Huang et al. (2018) developed an automated discharge imaging system to estimate floods during typhoon events by using LSPIV in river systems. Objective detection methods have been created based on improvements in image analysis and enhancement over water surfaces; these methods are used to study water and environmental pollution (Zhang et al. 2019). Image-based techniques have been used to investigate and quantify many natural phenomena. Additionally, this new method can show one- and two-dimensional visualizations of different applications. There are many factors that must be considered in image processing, such as the image resolution, image acquisition tools and image analysis software. In addition, image analysis goes through three general stages for image treatment: preprocessing, enhancement and information extraction (Anbarjafari 2014).

\subsubsection{Estimation of Peak Discharge Using the Slope-Area Method and Image Processing}

It is quite a challenge to manage and develop flash flood monitoring systems in arid regions due to the large-scale catchments and the lack of financial investments in the water sector. The slope-area method is a conventional technique used to quantify peak post-flood discharges in wadi systems; this method requires time and equipment for surveying. However, this method is an indirect measurement that has been used to study low-flow and ephemeral rivers and is currently less frequently used due to the large amount of required statistical analysis (Griffiths and McKerchar 2015). In this section, we used observed and field-measured data to calculate peak discharge in a wadi system and compared the data with the new method involving image processing. This approach was approved by Castillo et al. (2018) to be more suitable to provide sufficient cross-sectional measurements with less time and lower costs than the conventional method. With the high growth of unmanned aerial vehicle (UAV) technology, also called drones, UAVs have been utilized as instruments to extract information such as channel morphology and flood markers. In this research, we presented a novel technique for quantifying the post-flood peak discharge in a wadi system using imagery acquired by UAVs with photogrammetry analysis. 


\subsection{Methodology}

\subsubsection{Study Area and Data Collection}

The study area is Wadi Aluqq, a part of the Wadi Samail catchment in northern Oman with a drainage area of $136 \mathrm{~km}^{2}$ (Fig. 9.4). The main types of channel bed material in this basin include gravel and sand. This research was applied on a small-scale reach of a wadi channel that was surveyed by drone and satellite levelling instruments. Thirty-five images were acquired for the study reach by using a drone camera. The zenith of the camera was perpendicular to the channel bed with approximately $50 \%$ overlap between images. The camera resolution was $20 \mathrm{MP}$, or $5472 \times 3648$ pixels, which had a high efficiency in detecting high details of the wadi channel bed. Four ground control points (GCPs) were located over the reach and were marked with visible spray marks. These GCPs were distributed over the reach to calibrate the photogrammetry analysis and georeferenced into real-world units. Agisoft Metashape is a commercially available software that is used to generate dense cloud points to formulate a digital elevation model (DEM). A DEM was constructed based on the formulation of textural features and the detection of structural properties with a differentiation of features with similar spectra in the same region. Spray marks were placed on all elevation points obtained by the levelling instrument. We used the DEM to extract the same cross-sectional location for the levelling survey. Figure 9.5 shows the methodology approach used to estimate peak discharge with different techniques.

The peak discharge was calculated from the cross sections using the slope area method equations. A satellite levelling instrument was used to obtain three cross sections and flood markers. Additionally, 51 channel bed elevation points for the three cross sections with 22 flood marker elevation points were used to compute the peak discharge by using the slope-area method and Manning equation. The water slope surface was calculated from the flood marker elevation points. Wadi channel flow is a part of the hydrological process for which measurements represent the flood catchment scale. Water level gauging stations were used to detect high water marks with which to extract cross sections from DEMs (drone surveys) and measure the water depth of flows in wadi channels.

The cross section was divided into small areas to estimate the discharge and reduce the uncertainty in the vertical velocity profile. In the first step involving the camera installation and set-up, the camera was mounted on a road bridge across the wadi channel. The camera view covered the channel width with a visible selected GCP. The installed camera was operated by a power supply from batteries and used a memory card to record the flood events. On 28 October 2018, we recorded a flash flood event with approximately five hours of continuously recorded discharge. The discharge was estimated to be $6.3 \mathrm{~m}^{3} / \mathrm{s}$ from a rating curve that was constructed based on different slope area measurements. 


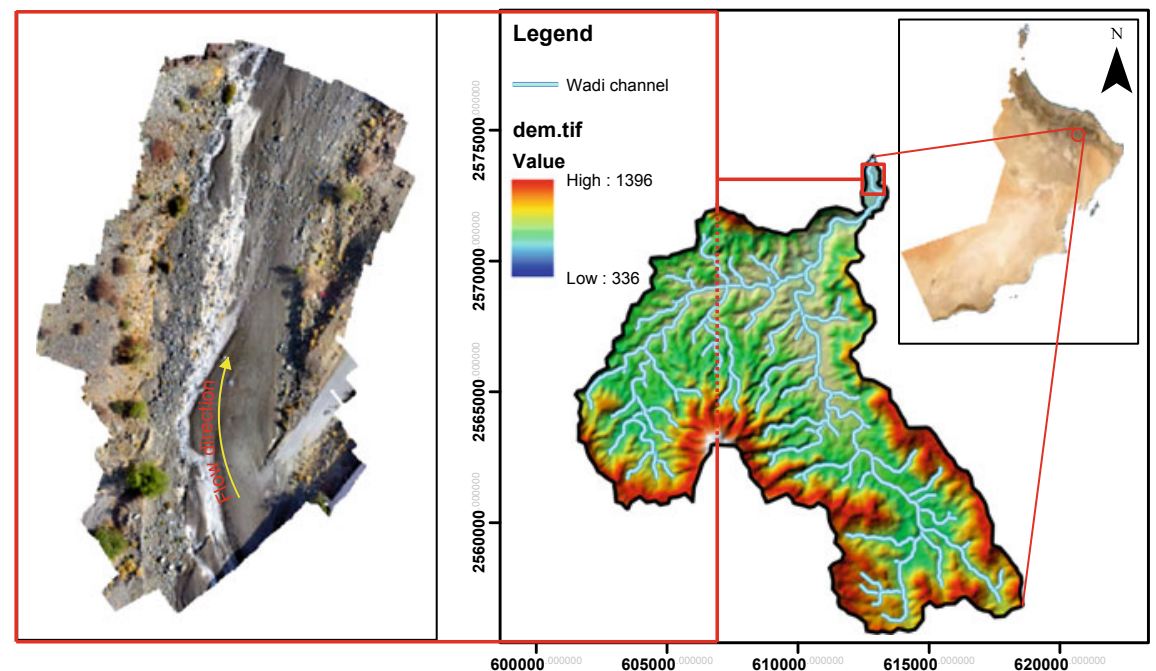

Fig. 9.4 a Drone survey of wadi channel bed; b location of Wadi Aluqq showing topographic elevation

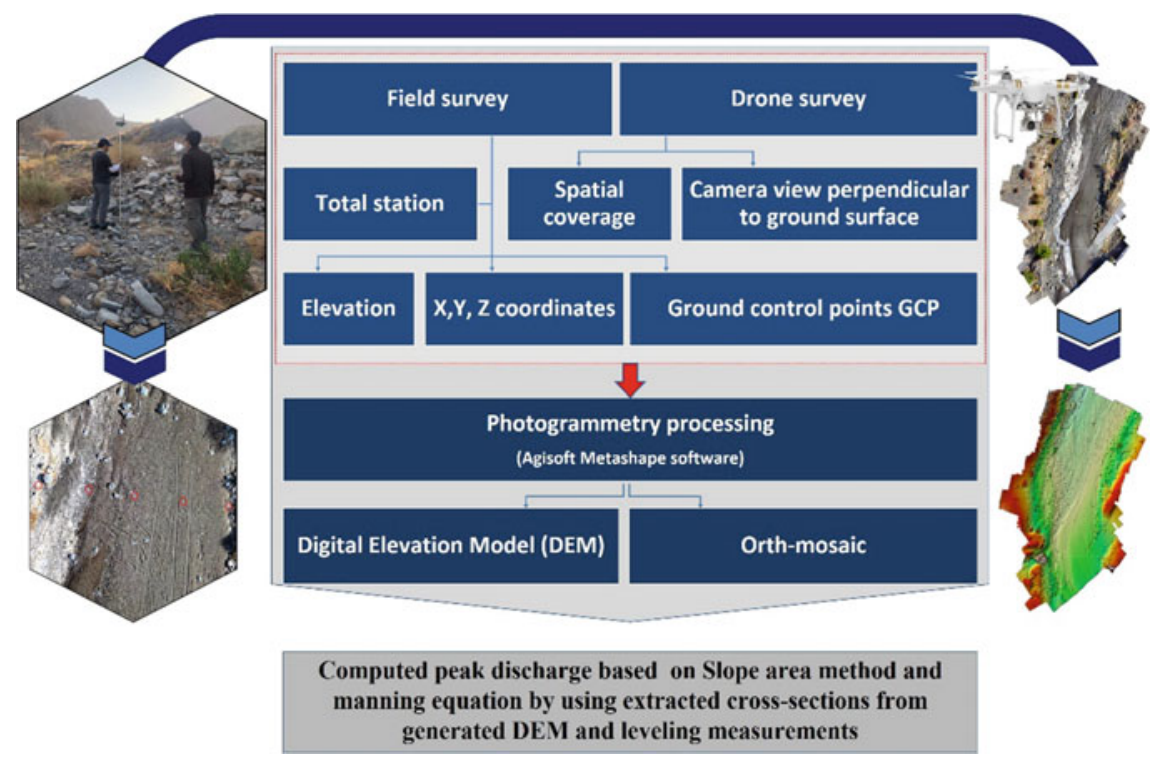

Fig. 9.5 Methodology for generating a digital elevation model (DEM) 


\subsubsection{Image Preprocessing}

The recorded video of the flash flood was converted into frames. The specification of the video was 30 frames per second (fps) with an image resolution of $1280 \times 720$ pixels. We enhanced the images by changing the contrast setting to improve the sediment tracers and natural floating debris to be clearer and more visible, which helped drive the flow patterns and directions when computing the surface velocity (Kantoush 2009). We selected six natural GCP features (stable rocks within the channel). The images were orthorectified to a plan-to-plan view by using the GCPs, and each pixel was projected and georeferenced based on the correction from the GCPs.

\subsubsection{Computation of Surface Flow Velocities by LSPIV}

The commercial software used to analyse surface flow velocity in this paper was Dantec Dynamics A/S, Denmark. In addition, there are other options of open-source software that can be used for such analyses, such as Fudda-LSPIV and PIV ImageJ. Series of images were uploaded into the software with a time interval of $0.03 \mathrm{~s}$ between frames. We analysed the images with the cross-correlation function for the LSPIV technique, dynamic filtration and statistical analysis of the images to obtain the computed flow velocity and flow pattern (Fujita et al. 1998). Natural tracers provided detection marks with which to involve the movements in an interrogation area (IA) by following the detection pixel with marker movements from the first frame to the second frame. In addition, the IA was surrounded by the search area (SA) to identify the vector pattern that moved out of this area (Coz et al. 2010). The outline of the IA was delimited by $64 \times 64$ pixels with $50 \%$ overlap to formulate correlation coefficients. The resulting surface flow velocities were averaged for all frames to obtain a statistical analysis that included the mean velocity, correlation coefficient, standard deviation and variance over all pixels to avoid uncertainty from invisible tracers in the water surface.

\subsubsection{Calculation of Discharge}

Figure 9.6a shows the visibility of the displacement of foam on the water surface. The white line shows the location of the cross section, which was used to calculate the discharge and analyse the surface flow velocities. We validated our results using three approaches (slope-area method, velocity-area method and average cross section). The Manning equation was utilized to estimate the flow velocity between three cross sections from field survey data (slope-area method). The velocity-area method was applied to calculate the discharge. We used 42 segments to measure the 


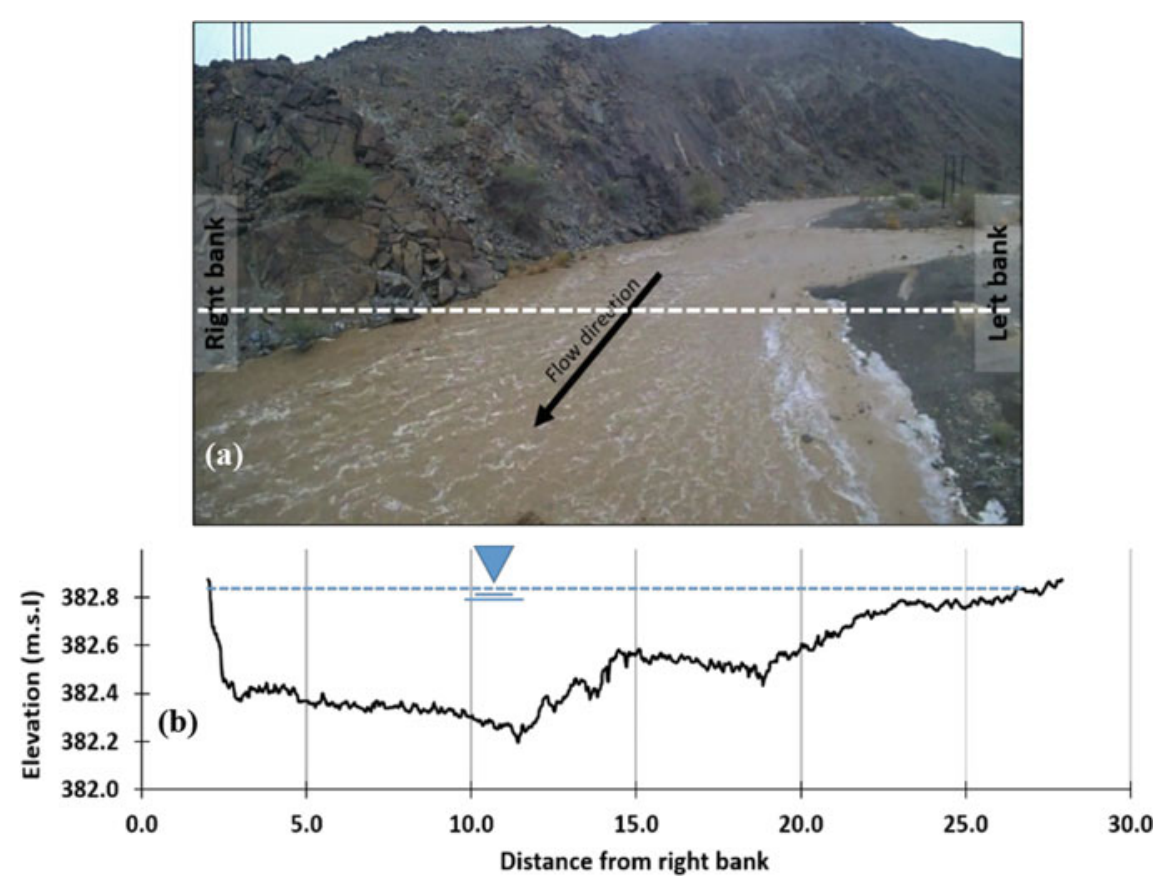

Fig. 9.6 a Original image showing the location of the cross-sectional velocity vectors; $\mathbf{b}$ the cross-sectional profile extracted from the DEM

surface velocity, $v_{i}$, with width, $\Delta y_{i}$, along the surveyed cross section. We summed the discharges as $Q=\sum_{i=1}^{n} \alpha v_{i} h_{i} \Delta y_{i}$, where $h_{i}$ was the water depth, defined based on the availability at each time step of the measured velocity to calculate discharge; $v_{i}$ is a function of the surface velocity; and $\alpha$ is the correction factor of 0.8 (Hauet et al. 2008). Figure 9.6b shows the bathymetry of the wadi cross section extracted from the digital elevation model (DEM). In addition, we obtained the levels of water markers from the field survey and validated them with the measured water levels.

\subsection{Results}

The accuracy of the photogrammetry analysis is shown in Fig. 9.7; the accuracy was determined by checking the correlation between the measured and computed elevation (DEM) of the cross section. With 15 elevation points, the results had a good fit, with $R^{2}=0.99$. However, we determined the mean square error (MSR) for those points, which was equal to less than one centimetre (MSE =0.027). Figure 9.7 shows that the obtained cross section (CS) from the field survey and extracted CS from the DEM matched well, but the CS from the DEM had high and 

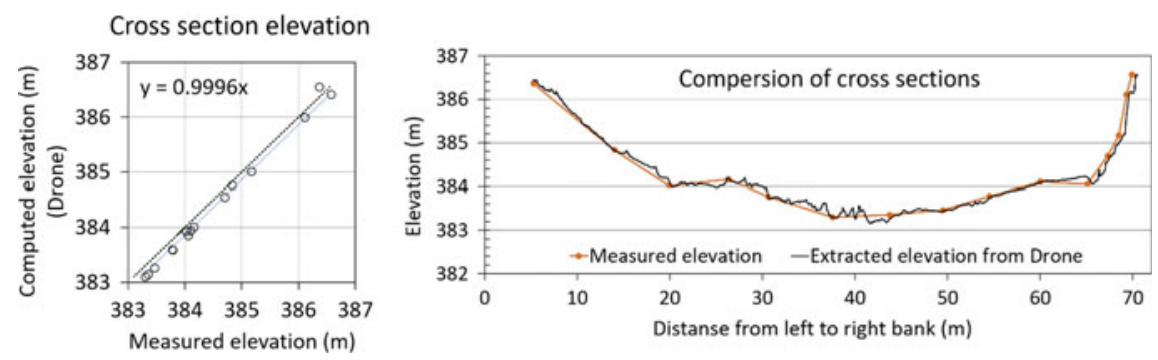

Fig. 9.7 Comparison between the generated DEM and measured cross section

precise elevation details over the whole cross section. We assume the peak discharge had uniform flow. Three cross sections were used to calculate the peak flood discharge, as presented in Fig. 9.8. The calculated peak discharge from the image processing technique was compared with the calculated peak discharge from the satellite levelling survey (Fig. 9.9). The DEM cross section included more details regarding the channel bed that could give reasonable estimations of peak discharge. Moreover, using drones for field surveys can clarify flood marks more easily than using conventional methods.

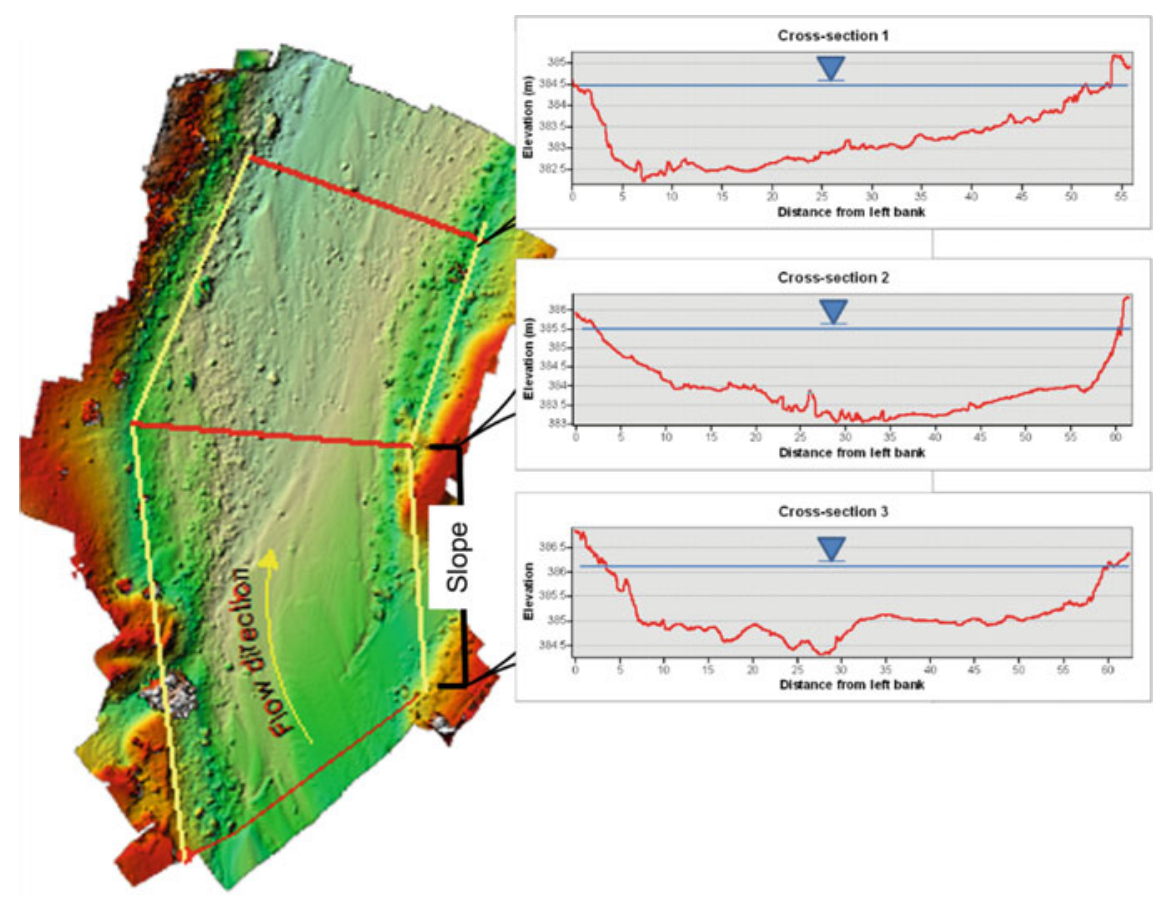

Fig. 9.8 Three cross sections used to estimate the peak discharge 


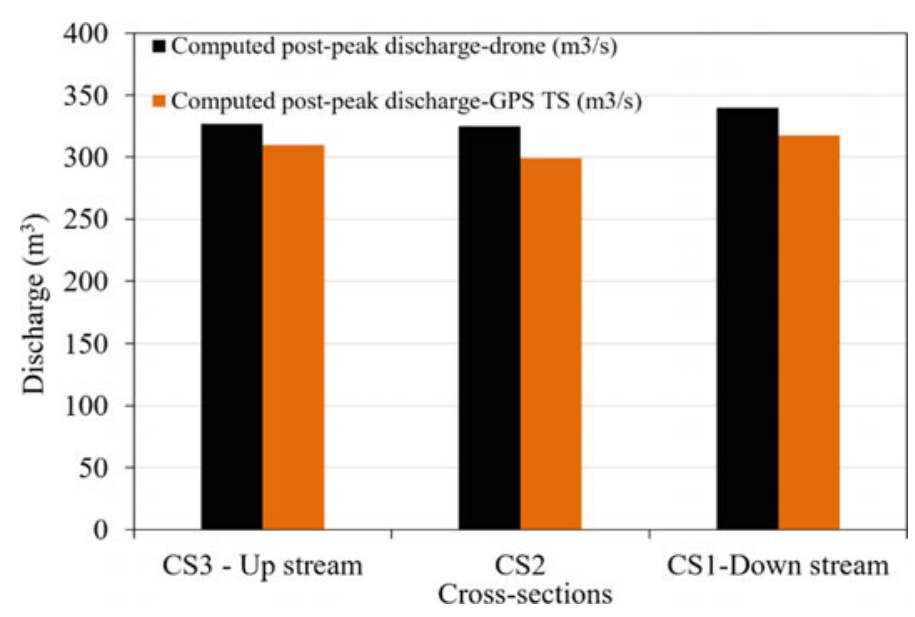

Fig. 9.9 Comparison between estimated discharges from the generated DEM and the measured elevation values

Additionally, the cross sections obtained through the levelling survey produced an underestimated peak discharge due to the unclear topography of the channel bed. The channel bed roughness was estimated based on soil materials in the wadi reach. To calculate cross-sectional areas, we used ArcGIS software and drew the $x$-, $y$ - and $z$-axes as polygons. The peak discharge estimated from the DEM was higher in all three cross sections than those obtained in the levelling survey. However, the satellite levelling survey simplified the cross sections of the wadi channel by obtaining elevation points for general topographical shapes with limited data points. The peak discharge obtained by this survey had similar results to that obtained by the drone survey.

\subsubsection{LSPIV Velocity Result}

Figure 9.10 shows the average velocity pattern in the surface velocities measured by LSPIV. The computational analysis provided LSPIV velocities over all flood surface extents. The averaged cross-sectional velocity obtained using LSPIV $(0.83 \mathrm{~m} / \mathrm{s})$ was compared with the velocity obtained with the slope-area method, which was computed based on the slopes between the cross sections and water marker elevations (Manning equation) and was equal to $0.7 \mathrm{~m} / \mathrm{s}$. Overall, there is reasonable agreement between both techniques, and the relation between the surface flow velocity and cross-sectional profile is shown in Fig. 9.11. We can see that there was a decrease in the velocity on the right bank during the peak and recession phases due to the effects of the channel bank (rock). 

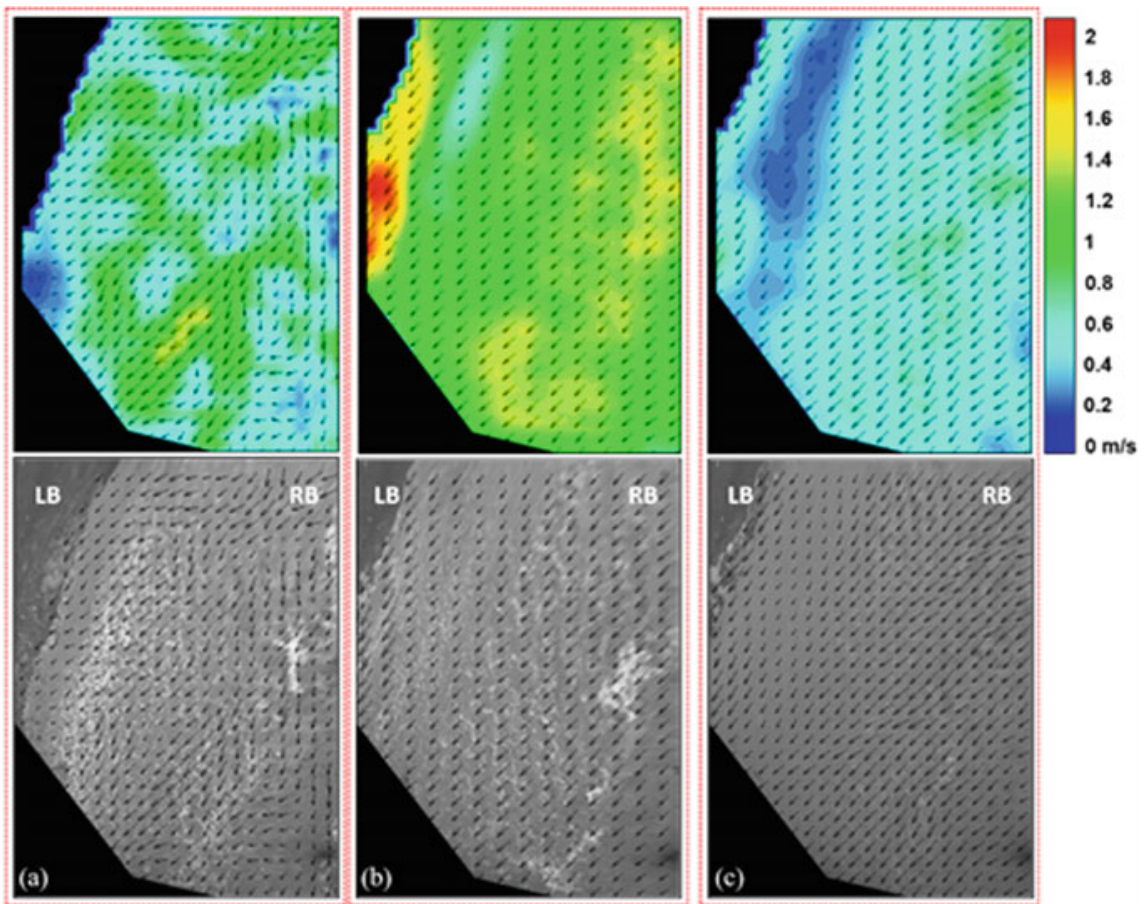

Fig. 9.10 Average flow patterns with velocity colour maps and orthorectified images using LSPIV for a the rising phase, $\mathbf{b}$ the peak phase and $\mathbf{c}$ the recession limbs of the flood event on 28 October 2018, where LB is the left bank and RB is the right bank (Al-Mamari et al. 2019 MDPIhydrology)

\subsubsection{LSPIV Discharge Result}

The LSPIV analysis of discharge was divided into three phases (rising, peak and recession). Figure 9.12 shows the LSPIV-estimated discharge compared with the computed discharge measured by the rating curve using field measurements. The LSPIV computation was used to calculate the discharges with the mean surface flow velocity and cross-sectional surface velocity distributions in different time intervals. The mean velocity of the LSPIV-estimated discharge showed underestimated values compared to those obtained from the conventional method; on the other hand, the cross-sectional surface velocity of the LSPIV-estimated discharge (approximately $6.48 \mathrm{~m}^{3} / \mathrm{s}$ ) showed very good agreement with the computed discharge from the rating curve and field measurements, which equalled $6.34 \mathrm{~m}^{3} / \mathrm{s}$. 


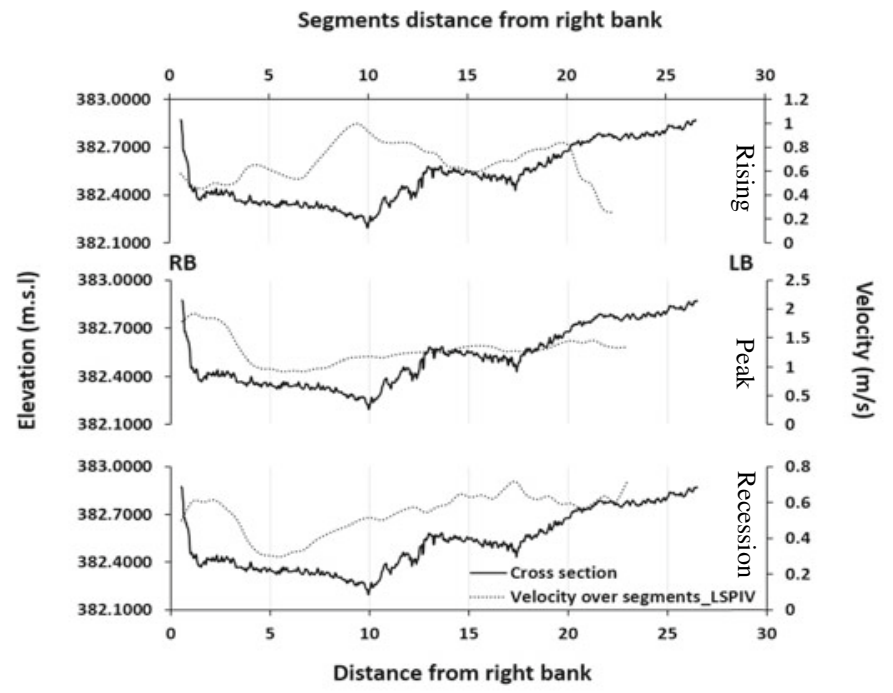

Fig. 9.11 Relation between the surface flow velocity and cross-sectional profile (Al-Mamari et al. 2019 MDPI-hydrology)

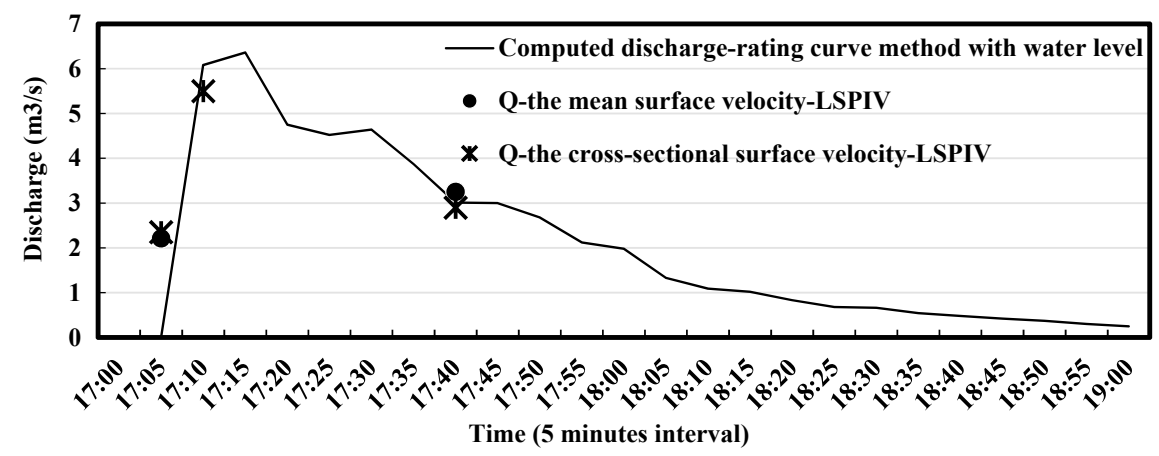

Fig. 9.12 Result of computed discharge from the LSPIV and slope-area methods (Al-Mamari et al. 2019 MDPI—hydrology)

\subsection{Conclusions}

Hydrological data is an important component in evaluating and managing water resources. In this paper, the investigation of post-peak flood discharge and a real-time discharge measurement method for wadi flash floods in arid regions using photogrammetry and LSPIV techniques was presented. Image-based techniques have been used to quantify post-peak flood discharge for wadi systems by generating DEMs from drone images with fully automated processing workflows. 
To generate a DEM, several images with approximately $50 \%$ overlap between them and ground control points are required to improve the processing performance. We calibrated and validated the new approach by using a levelling field survey. Based on the analysis, the mean square error between the extracted cross sections from the field survey and the DEM was very small and was equal to 0.027. The new method is easy and has acceptable accuracy compared with other, conventional methods. The combination of techniques proved that image processing can provide sufficient data and information. Photogrammetry analysis is very sensitive to shadows created by vegetation or any objects. The LSPIV technique was utilized to measure the surface flow velocity with a cross-sectional profile from the DEM. The results show good agreement between the surface flow velocity and slope-area method; the estimated peak discharge in the LSPIV method was $6.4 \mathrm{~m}^{3} / \mathrm{s}$, and that from the slope-area method was $6.3 \mathrm{~m}^{3} / \mathrm{s}$. However, the investigation of estimated discharge was very efficient and can be improved with a high-resolution camera and optimal camera angle. This technique will provide an opportunity to measure post-peak flood discharges in any topographic conditions and represents a cost-effective technique to monitor flash floods. However, these techniques require a visible tracer and floating objects in the water surface to detect discharge velocities. Future research will be concerned with developing a real-time monitoring system in wadi basins for multitask purposes, such as early warning systems and online real-time measurements.

\section{References}

Abdel-Fattah M, Kantoush S (2016) Hydrological modelling of flash flood in Wadi Samail, Oman. Annual of Disaster Prevention Research Institute, Kyoto University

Al-Mamari MM, Kantoush S, Kobayashi S, Sumi T, Saber M (2019) Real-time measurement of flash-flood in a wadi area by LSPIV and STIV. Hydrology 6:27

Anbarjafari G (2014) https://sisu.ut.ee/imageprocessing/book/1. University of Tartu

Castillo C, Marín-Moreno VJ, Pérez R, Muñoz-Salinas R, Taguas EV (2018) Accurate automated assessment of gully cross-section geometry using the photogrammetric interface FreeXSapp. Earth Surf Process Landforms 43(8):1726-1736

Coz J, Hauet A, Pierrefeu G, Dramais G, Camenen B (2010) Performance of image-based velocimetry (LSPIV) applied to flash-flood discharge measurements in Mediterranean. J Hydrol 394:42-52

Dalyrmple T, Benson MA (1967) Measurement of peak discharge by the slope-area method, USGS

Detert M, Weitbrecht V (2015) A low-cost airborne velocimetry system: proof of concept. J Hydraul Res 53(4):532-539

Fujita I, Notoya Y, Tain K, Tateguchi S (2019) Efficient and accurate estimation of water surface velocity in STIV. Environ Fluid Mech 19(5):1363-1378

Fujita I, Muste M, Kruger A (1998) Large-scale particle image velocimetry for flow analysis in hydraulic engineering applications. J Hydraul Res 36(3):397-414

Griffiths GA, McKerchar AI (2015) Estimation of flood peak discharge by the slope-area method. J Hydrol 54(2):153-160 
Harpold AA, Mostaghimi S, Vlachos PP, Brannan K, Dillaha T (2006) Stream discharge measurement using a large-scale particle image velocimetry (LSPIV) prototype. Transactions of the ASABE 49:1791-1805

Hauet A, Creutin JD, Belleudy P (2008) Sensitivity study of large-scale particle image velocimetry measurement of river discharge using numerical simulation. J Hydrol 349(1-2):178-190

Huang WC, Young CC, Liu WC (2018) Application of an automated discharge imaging system and LSPIV during typhoon events in Taiwan. Water 10(3)

Johnson MV (1977) Channel geometry and wadi flows, Batinah coast, Sultanate of Oman

Kantoush SA, Schleiss AJ (2009) Large-scale PIV surface flow measurements in shallow basins with different geometries. J Vis 12(4):361-373

Muto Y, Baba Y, Aya S (2002) Velocity measurements in open channel flow with rectangular embayments formed by Spur dykes. Annual of Disaster Prevention Research Institute, Kyoto University

Public Authority for Water Resource (1983) Surface water gauging station network of the Sultanate of Oman. PAWR 83-2

Sen Z (2008) WADI/hydrology. CRC Press

Smith MW, Carrivick JL, Hooke J, Kirkby MJ (2014) Reconstructing flash flood magnitudes using 'structure-from-motion': a rapid assessment tool 519(2014):1914-1927

Sun X, Shiono K, Chandler JH, Rameshwaran P, Sellin RHJ, Fujita I (2010) Discharge estimation in small irregular river using LSPIV. In: Proceedings of the Institution of Civil Engineers-Water Management. Vol 163, no 5, pp 247-254

Zhang L, Zhang Y, Zhang Z, Shen J, Wang H (2019) Real-time water surface object detection based on improved faster R-CNN. Sensors 19(16):3523

Open Access This chapter is licensed under the terms of the Creative Commons Attribution 4.0 International License (http://creativecommons.org/licenses/by/4.0/), which permits use, sharing, adaptation, distribution and reproduction $\gg$ in any medium or format, as long as you give appropriate credit to the original author(s) and the source, provide a link to the Creative Commons license and indicate if changes were made.

The images or other third party material in this chapter are included in the chapter's Creative Commons license, unless indicated otherwise in a credit line to the material. If material is not included in the chapter's Creative Commons license and your intended use is not permitted by statutory regulation or exceeds the permitted use, you will need to obtain permission directly from the copyright holder. 